\title{
Cellulose products modified with monomeric and gemini surfactants: antimicrobial aspects
}

\author{
A. Koziróg • B. Brycki · K. Olejnik • A. Wysocka-Robak • P. Dębska-Winkler
}

Received: 18 October 2018/Accepted: 3 May 2019/Published online: 13 May 2019

(C) The Author(s) 2019

\begin{abstract}
The aim of this study was to examine the impact of microbiocides on the reduction of the microbial population on paper in order to protect it against biodeterioration. The cellulose products were modified with the cationic gemini surfactant hexamethylene-1,6-bis-(N,N-dimethyl-N-dodecylammonium bromide) $\mathrm{C} 6$ and its monomeric analog (didecyldimethylammonium chloride) DDAC. The microbiocides were introduced into the paper by coating and spraing. In the coating method the microbiocides were mixed with starch solution and applied to paper surface as a wet film with a thickness of 24 and $50 \mu \mathrm{m}$. In the spraying method the surfactants were applied at $3 \%$ concentration in water to get $0.005 \mathrm{ml} / \mathrm{cm}^{2}$ of
\end{abstract}

Electronic supplementary material The online version of this article (https://doi.org/10.1007/s10570-019-02475-0) contains supplementary material, which is available to authorized users.

A. Koziróg $(\bowtie) \cdot$ P. Dębska-Winkler

Faculty of Biotechnology and Food Sciences, Institute of Fermentation Technology and Microbiology, Lodz

University of Technology, Lodz, Poland

e-mail: anna.kozirog@p.lodz.pl

B. Brycki

Laboratory of Microbiocides Chemistry, Faculty of Chemistry, A. Mickiewicz University in Poznan, Poznan, Poland

K. Olejnik · A. Wysocka-Robak

Institute of Papermaking and Printing, Lodz University of

Technology, Lodz, Poland paper. Experiments were performed with moulds of the genera Aspergillus, Penicillium, Chaetomium and Trichoderma and bacteria represented by the genera Bacillus and Pseudomonas. The antimicrobial properties of the paper modified with surfactants were determined by qualitative and quantitative methods. The zones of inhibition were measured using the parallel streak method. Macroscopic assessment of mould growth on the surface of the paper samples was performed over 21 days of incubation. In quantitative analysis, the survival rate of microorganisms on the modified paper samples was determined over $24 \mathrm{~h}$. Aspergillus brasiliensis was the least sensitive mould, with no observable inhibition zones. No growth of this mould was observed either on or underneath the sample. Both of the surfactants applied as coatings or sprays protected the paper effectively against the growth of bacteria and mould. However, the spraying method is simpler to use. Over $24 \mathrm{~h}$, the number of spores and bacteria in all the samples containing surfactants was reduced to below $1 \log / 10 \mathrm{~cm}^{2}$ (reduction factor up to $99.9 \%$ ). The compounds may therefore be applied as antimicrobial agents for the protection of paper. 


\section{Graphical abstract}
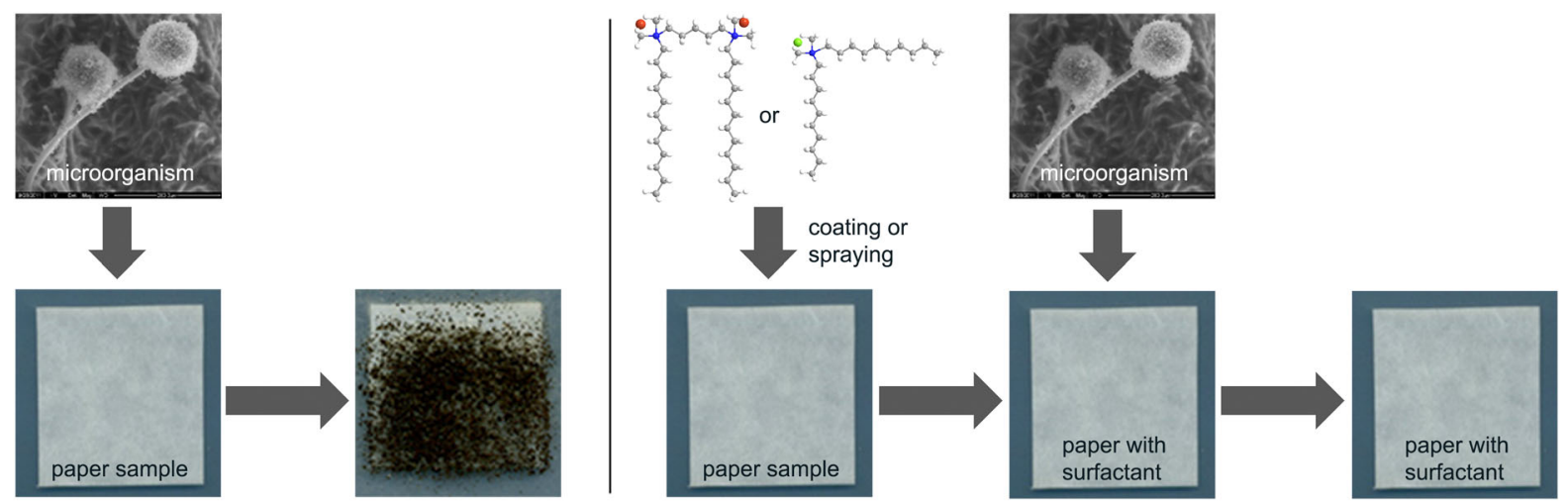

Keywords Monomeric/gemini surfactants . Antimicrobial activity - Cellulose protection . Antimicrobial paper

\section{Introduction}

The process of papermaking mostly uses natural plant raw materials. The main group of compounds from which plant fibres are built are the polysaccharides, in particular cellulose. Starch is often used as a dry strength additive in papermaking. These compounds can be utilized as nutrients by microorganisms. On one hand, this is positive, since it makes paper and paper products more biodegradable and environmentally friendly. However, it may be undesirable, especially during paper use or storage.

Microorganisms can appear at an early stage of the papermaking process. They may be spread by water (which is used in large amounts in papermaking process), by air, or by raw materials and additives, especially when recycled pulps (which are a source of carbon and nitrogen for microorganisms) are employed (Flemming et al. 2013). Bacteria which form biofilms, such as the genus Pseudomonas, are particularly problematic. These bacteria cause the excretion of excessive amounts of slime, which clogs pipelines and machines such as sieves, leading to corrosion and even sheet-break (Goyer and Lavoie 2001; Huang et al. 2009). The final product may also be susceptible to the growth of microorganisms which enter paper during storage. The microorganisms with cellulolytic abilities, such as the genera Cellulomonas,
Cythophaga, Pseudomonas or Streptomyces, are the most frequently isolated from paper (Manente et al. 2012).

Moulds are also often present during the production of paper and paper products. Those most frequently isolated are Aspergillus, Penicillium, Trichoderma and Fusarium, which require less moisture, as well as Alternaria, Chaetomium and Stachybotrys, which are capable of hydrolyzing very resistant cellulose fibres. These fungi contribute to reduce the technological parameters and strength of cellulose pulp, which can lead to considerable weight loss of up to $48 \%$. In the final product, their effects may include reduced paper strength and numerous discolorations (Fabbri et al. 1997; Stobińska and Zyska 2005; Pinzari et al. 2006).

In recent years, there has been increasing interest in antimicrobially active cellulose products i.e. paper. Such paper could find uses in hospitals, offices, food production, cosmetics, medicines and toiletry products. Both inorganic and organic compounds can be used as antimicrobial agents, most notably silver nanoparticles (Amini et al. 2016), zinc oxide (Martins et al. 2013; Pang et al. 2016), titanium dioxide (Wang et al. 2013), chitosan and its derivatives (Vartiainen et al. 2004), essential oils (Rodríguez et al. 2007), dendrimers like polyamidoamine (PAMAM) or polypropylene imine (PPI) (Akbari and Michal Kozłowski 2018) and quaternary ammonium salts (Nechita et al. 2015). These substances can be introduced directly into the paper pulp (Ling et al. 2013) or used in numerous processes of surface refinement. They may be coated onto the surface of paper using an automatic coater with Meyer rods (Nechita et al. 2015) or sprayed using special nozzles 
(Battisti et al. 2017). It is essential to use substances that which are readily soluble in water, and which modify the properties of the paper without causing undesirable reactions with other chemicals or accelerated machine wear.

In the present study, the quaternary ammonium salts DDAC (didecyldimethylammonium chloride) and a double quaternary ammonium salt, gemini surfactant hexamethylene-1,6-bis- (N, N-dimethyl-Ndodecylammonium bromide) $\mathrm{C} 6$, were used as antimicrobial agents for the preservation of paper (Fig. 1).

The cationic gemini surfactant contains two amphiphilic groups in its structure. In a previous work by the authors (Koziróg and Brycki 2015), gemini surfactants were demonstrated to be highly effective against both bacteria and microscopic fungi. The minimal inhibitory concentration (MIC) for some microorganisms was up to 70 times lower in comparison to monomeric compounds. However, the antimicrobial activity of surfactants on paper has not been investigated previously. The aim of this study was to examine the impact of microbiocides on the reduction of the microbial population on paper in order to protect it against biodeterioration.

\section{Materials and methods}

Strain and growth conditions

The moulds used in the study were Aspergillus brasiliensis ATCC 16404 (previously known as A. niger), Aspergillus terreus ATCC 10020, Penicillium chrysogenum ATCC 60739, Penicillium aurantiogriseum ATCC 18382, Trichoderma viride and Chaetomium globosum, both isolated from paper surfaces. The strains were stored on Malt Extract Agar (MEA) slants (MERCK, Germany) at $4{ }^{\circ} \mathrm{C}$. Prior to each experiment, the strains were subcultured in MEA medium at $28{ }^{\circ} \mathrm{C}$ for $4-5$ days until the conidia were fully mature. Spore suspensions were prepared by washing the conidia from the agar slants using deionized sterilized water with $0.1 \%$ Tween 80 and stirring. In the case of C. globosum, the perithecia and asci were gently squeezed using a sterile glass rod to release the ascospores. The concentrations of spores in the initial water suspensions were evaluated using a Thoma chamber and adjusted to $1.0-2.0 \times 10^{6}$ coni$\mathrm{dia} / \mathrm{ml}$. Experiments were also performed with two strains of bacteria: Pseudomonas aeruginosa PB_1 isolated from plant biomass (Koziróg et al. 2018) and Bacillus subtilis. The biological material was stored on Tryptic Soy Agar (TSA) slants (MERCK, Germany) at $4{ }^{\circ} \mathrm{C}$. Prior to each experiment, the strains were subcultured in Tryptic Soy Broth (TSB) medium (MERCK, Germany) and incubated for $24 \mathrm{~h}$ at $37{ }^{\circ} \mathrm{C}$ and $30^{\circ} \mathrm{C}$ for $P$. aeruginosa and $B$. subtilis, respectively. Inoculum was prepared in sterile $0.95 \%$ saline and the concentration was adjusted to yield $1.0-2.0 \times 10^{7} \mathrm{cfu} / \mathrm{ml}$.

Antimicrobial agents

Hexamethylene-1,6-bis-(N,N-dimethyl-N-dodecylammonium bromide) $\mathrm{C} 6$ and didecyldimethylammonium chloride DDAC were used as antimicrobial agents. The gemini surfactant (C6) was synthesized in a reaction described by Koziróg et al. (2017). Didecyldimethylammonium chloride is commercially available (Aldrich, Germany).

Antimicrobial resistance of starch modified with biocides

Paper samples were coated with starch modified with biocides. Commercial, wheat starch C*Flex 20002
A

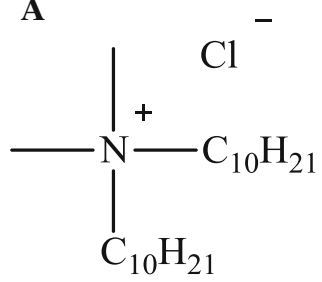

B

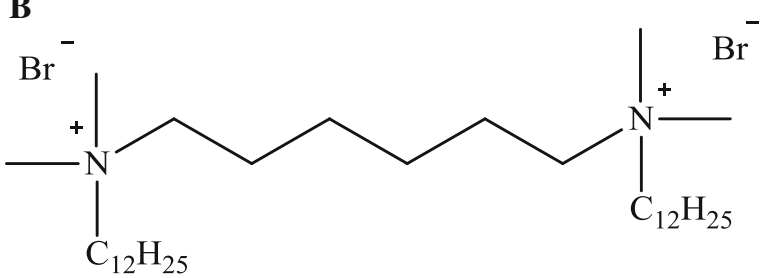

Fig. 1 Structure of a didecyldimethylammonium chloride DDAC and b hexamethylene-1,6-bis-(N,N-dimethyl-N-dodecylammonium bromide) C6 
produced by Cargill Company was used for this purpose. In order to obtain an aqueous starch solution, gelatinization was carried out at the temperature of $60{ }^{\circ} \mathrm{C}$. The starch and surfactant mixtures were tested for their resistance to bacteria and mould. To each tube were added $1 \mathrm{ml}$ of a solution containing starch and one of the tested biocides. The monomeric and dimeric surfactants were both used at concentrations of $1-5 \%$. In the next step, the compounds with starch were mixed with $1 \mathrm{ml}$ of the conidial suspension $\left(1.5 \times 10^{6}\right.$ conidia/ml $)$ or bacterial suspension $\left(1.5 \times 10^{7} \mathrm{cfu} /\right.$ $\mathrm{ml})$. Conidial and bacterial suspensions in 3\% starch without the tested biocides were used as control samples ( $1 \mathrm{ml} \mathrm{3 \%}$ starch $+1 \mathrm{ml}$ inoculum). Finally, the samples were incubated for $24 \mathrm{~h}$ at $28{ }^{\circ} \mathrm{C}, 30^{\circ} \mathrm{C}$ and $37{ }^{\circ} \mathrm{C}$ for the moulds, Bacillus subtilis and Pseudomonas aeruginosa, respectively. The samples were then inspected for signs of macroscopic growth. To confirm the macroscopic observations, one loopful of each suspension was transferred to a Petri dish with solid culture media, i.e. TSA for bacteria and MEA for moulds. Macroscopic observations were performed after another $24 \mathrm{~h}$.

\section{Preparation of paper samples}

Commercial, bleached softwood pine kraft pulp (BSK) was used to prepare laboratory handsheets. The pulp parameters were as follows: initial moisture content 94.5\%; Schopper-Riegler value SR-14. The pulp was beaten in a PFI mill (Stromberg, Finland) following the TAPPI T-248 standard method, to Schopper-Riegler freeness of SR-35. Laboratory sheets of $70 \mathrm{~g} / \mathrm{m}^{2}$ were formed in a Rapid-Köthen apparatus produced by the Labor-Meks Company (Poland), according to standard ISO 5269-2 (2004).

To obtain higher resistance to microorganisms, the paper sheets were sprayed with $3 \%$ DDAC or C6 at $120^{\circ}$ using Lechler no. 09210616 spray nozzles. The positions of each of the nozzles were adjusted so that $0.005 \mathrm{ml} / \mathrm{cm}^{2}$ of the solution was applied uniformly to the surface of the paper samples. The biocides were also applied in starch solution to the paper surface using a standard coating process. This operation was carried out at a speed of $16 \mathrm{~cm} / \mathrm{s}$ with the use of an IPP/TUL (Poland) automatic coater ('Control Coater'), using standard Mayer rods No. 3 (K-bar) and 5 , giving wet film thicknesses of $24 \mu \mathrm{m}$ and $50 \mu \mathrm{m}$. The samples of coated paper were heat treated in a KBC-32 drier (WAMED, Poland) at $98{ }^{\circ} \mathrm{C}$ for $15 \mathrm{~min}$. Table 1 shows the samples used in our study.

Antimicrobial properties of paper modified with surfactants—a qualitative method

The AATCC 147 (2011) standard was used to assess the antimicrobial activity of the paper. The agar surfaces of the MEA and TSA media were streaked with inocula of test moulds and bacteria, respectively. The inocula were prepared following the method described in point 2.1. Paper samples $1 \times 5 \mathrm{~cm}^{2}$ in size were placed perpendicularly on each of the media surfaces streaked with test microorganisms. All samples were then incubated for $24 \mathrm{~h}$ : at $30^{\circ} \mathrm{C}$ for Bacillus subtilis, $37^{\circ} \mathrm{C}$ for Pseudomonas aeruginosa and at $28{ }^{\circ} \mathrm{C}$ for the moulds. Next, the activity of the surfactants was compared to that of the control sample without biocides, based on the criteria shown in Table 2.

Antifungal properties of paper modified with surfactants-TAPPI T-487 test

The TAPPI T-487 test was used to assess the resistance of the paper samples to the development of mould. Test samples $5 \times 5 \mathrm{~cm}^{2}$ in size were placed on the surfaces of the mineral media and inoculated with fungal spores at a concentration of $10^{2}$ or $10^{6}$ conidia/ml. Paper samples without surfactants were used as controls. All samples were incubated at $28{ }^{\circ} \mathrm{C}$, HR $80 \pm 2 \%$ for 21 days. Macroscopic observations were made every 7 days. The resistance of the paper to moulds was evaluated based on the criteria described in Table 3.

Antimicrobial properties of paper modified with surfactants-a quantitative method

The AATCC 100 (2012) antimicrobial standard test method was used for quantitative evaluation of the antimicrobial activity of the paper. Modified paper samples $2 \times 5 \mathrm{~cm}^{2}$ in size were placed in sterile Petri dishes. The paper swatches were inoculated with $0.2 \mathrm{ml}$ of the microbial suspension with a standardized concentration of microorganisms: $10^{6}$ conidia $/ \mathrm{ml}$ for moulds and $10^{7} \mathrm{cfu} / \mathrm{ml}$ for bacteria. The levels of moulds and bacteria on the paper swatches were determined at time $\mathrm{t}=0 \mathrm{~h}$ and $24 \mathrm{~h}$. Half of the 
Table 1 Paper samples modified with biocides

\begin{tabular}{lll}
\hline Sample & Type of biocide & Method of biocide application \\
\hline 1/C6 coating & $3 \% 12-6-12$ & $24 \mu \mathrm{m}$, coating \\
& $2 \%$ starch & \\
2/C6 coating & $3 \% 12-6-12$ & $50 \mu \mathrm{m}$, coating \\
& $2 \%$ starch & \\
1/DDAC coating & $3 \%$ DDAC & $24 \mu \mathrm{m}$, coating \\
& $2 \%$ starch & $50 \mu \mathrm{m}$, coating \\
2/DDAC coating & $3 \%$ DDAC & \\
& $2 \%$ starch & $0,005 \mathrm{ml} / \mathrm{cm}^{2}$, spray \\
C6 spray & $3 \% 12-6-12$ & $0,005 \mathrm{ml} / \mathrm{cm}^{2}$, spray \\
DDAC spray & $3 \%$ DDAC & \\
\hline
\end{tabular}

Table 2 Interpretation of results for antimicrobial activity of papers-qualitative method

\begin{tabular}{lll}
\hline $\begin{array}{l}\text { Growth inhibition zone } \\
(\mathrm{mm})\end{array}$ & $\begin{array}{l}\text { Description of growth of microorganisms compared to the control sample without an } \\
\text { active agent }\end{array}$ & Result \\
\hline$>1$ & $\begin{array}{l}\text { Growth inhibition zone greater than } 1 \mathrm{~mm} \text {, no growth under the sample } \\
\text { Growth inhibition zone up to } 1 \mathrm{~mm}, \text { no growth under the sample }\end{array}$ & Good effect \\
$0-1$ & No growth inhibition zone, no growth under the sample & Boundary \\
0 & No growth inhibition zone, almost no growth under the sample \\
0 & No growth inhibition zone, growth under the sample reduced by $50 \%$ & Insufficient \\
effect & No growth inhibition zone, slightly reduced or normal growth & \\
0 & &
\end{tabular}

Table 3 Assessment of paper resistance to mould growth on the basis of TAPPI T-487 test

\begin{tabular}{lll}
\hline Duration of incubation (days) & Macroscopic observations & Rates of fungus resistance \\
\hline 7 & Growth of moulds on sample & No fungus resistance \\
14 & No growth during first week but sparse growth after 2 weeks & Moderate fungus resistance \\
21 & No growth of moulds & Fungus resistance \\
\hline
\end{tabular}

samples were placed in a climatic chamber (BINDER) and incubated overnight at $28{ }^{\circ} \mathrm{C}, \mathrm{HR} 80 \pm 2 \%$. The remainder of the samples at time $\mathrm{t}=0$ were transferred to a $10 \mathrm{ml}$ mixture of saline and neutralizers and shaken for $10 \mathrm{~min}$. A series of tenfold dilutions was made and the plate method used to determine the number of microorganisms. The TSA medium was used for bacteria and the MEA medium for moulds. The plates were incubated at $30{ }^{\circ} \mathrm{C}$ for Bacillus subtilis, $37^{\circ} \mathrm{C}$ for Pseudomonas aeruginosa and at $28{ }^{\circ} \mathrm{C}$ for the moulds. After $24 \mathrm{~h}$, all colonies were counted and the result expressed as $\log \left(\mathrm{cfu} / 10 \mathrm{~cm}^{2}\right.$ or conidia $/ 10 \mathrm{~cm}^{2}$ ). Additionally, the survivability of A.brasiliensis conidia was calculated after $1 \mathrm{~h}, 3 \mathrm{~h}$ and 6 h. For each sample, the reduction coefficient $\mathrm{R}$ was calculated using the Eq. (1):

$\mathrm{R}=\left(\mathrm{N}_{0}-\mathrm{N}\right) \times 100 / \mathrm{N}_{0}$

where $\mathrm{N}_{0}$ is the number of colonies detected from the control paper and $\mathrm{N}$ is the number of colonies detected from papers with biocides ( $\mathrm{Li}$ et al. 2016). 


\section{Results and discussion}

Antimicrobial properties of starch

with monomeric/gemini surfactants

The first stage of the study investigated the antimicrobial properties of 3\% starch with 1-5\% surfactants (Table 1S-supplement).

No growth of microorganisms was observed for any sample containing surfactants in solid or liquid media. The control sample (without surfactants) gave a positive result, as growth was detected of bacteria and moulds. This indicates that starch does not inhibit microbial growth, which is in agreement with reports by other researchers (Tudorachi et al. 2000; Shogren et al. 2003).

Antimicrobial properties of paper modified with surfactants-qualitative method

The effect of adding monomeric and gemini surfactants to paper samples was tested against 7 strains of mould and 2 strains of bacteria. Table 4 presents the zones of growth inhibition measured in $\mathrm{mm}$ for 2 tested compounds.

According to the criteria described in Table 2 (see methodology section), all samples containing surfactants had good antimicrobial properties. In the case of moulds, the largest zones of growth inhibition were observed for C. globosum $(0.5-3.0 \mathrm{~mm})$ and $P$. auratiogriseum $(0.5-2.5 \mathrm{~mm})$. No clear zones around the paper samples were detected for A. brasiliensis (Table 4, Fig. 2). However, the growth of this mould was inhibited both on the surface and underneath the sample. In the case of bacteria, the inhibition zones were larger $(0.5-6.75 \mathrm{~mm})$ for the Gram negative $P$. aeruginosa than with Gram positive $B$. subtilis (0-1.25 mm).

In a study of the antimicrobial activity of paper modified with $\mathrm{ZnO}$ nanorods, Jaisai et al. (2012) found that Gram negative $E$. coli were more sensitive than $S$. aureus. However, the opposite correlation between Gram positive and negative bacteria has been reported in a study by Pang et al. (2016). In their investigation of the antimicrobial properties of paper coated with sodium-lignosulfonate-stabilized $\mathrm{ZnO}$ nanoparticles, the authors obtained better antibacterial activity against Gram positive $B$. subtilis in comparison to Gram negative E. coli. On the other hand, Ghorbani (2014), who explored coating silver nanoparticles on paper, reports identical results both for E. coli and Gram positive $S$. aureus (zone of inhibition: $4 \mathrm{~mm}$ ). These different findings may be due to the different chemical compositions of the antimicrobial agents and how they bind with paper (Vartiainen et al. 2004). In our study, we applied cationic compounds, which

Table 4 Zones of microbial growth inhibition $(\mathrm{mm})$ for paper modified with surfactants

\begin{tabular}{|c|c|c|c|c|c|c|}
\hline \multirow[t]{3}{*}{ Tested microorganisms } & \multicolumn{6}{|c|}{ Type of sample } \\
\hline & \multicolumn{4}{|l|}{ Coating } & \multicolumn{2}{|l|}{ Spray } \\
\hline & 1/C6 & 2/C6 & 1/DDAC & 2/DDAC & C6 & DDAC \\
\hline \multicolumn{7}{|l|}{ Moulds } \\
\hline A. brasiliensis & $0.00 \pm 0.00$ & $0.00 \pm 0.00$ & $0.00 \pm 0.00$ & $0.75 \pm 0.5$ & $0.00 \pm 0.00$ & $0.00 \pm 0.00$ \\
\hline A. terreus & $0.00 \pm 0.00$ & $0.75 \pm 0.50$ & $1.00 \pm 0.00$ & $1.75 \pm 0.50$ & $0.50 \pm 0.00$ & $1.75 \pm 0.50$ \\
\hline A. versicolor & $0.50 \pm 0.50$ & $0.75 \pm 0.50$ & $0.75 \pm 0.50$ & $1.25 \pm 0.50$ & $1.25 \pm 0.50$ & $1.00 \pm 0.00$ \\
\hline P. chrysogenum & $0.00 \pm 0.00$ & $0.00 \pm 0.00$ & $1.50 \pm 0.58$ & $2.00 \pm 0.00$ & $0.75 \pm 0.50$ & $1.00 \pm 0.00$ \\
\hline P. aurantiogriseum & $1.50 \pm 0.58$ & $2.00 \pm 0.00$ & $1.00 \pm 0.00$ & $1.25 \pm 0.50$ & $0.50 \pm 0.50$ & $2.50 \pm 0.58$ \\
\hline T. viride & $0.00 \pm 0.00$ & $0.00 \pm 0.00$ & $1.00 \pm 0.00$ & $1.00 \pm 0.00$ & $1.00 \pm 0.00$ & $0.50 \pm 0.00$ \\
\hline C. globosum & $0.50 \pm 0.50$ & $1.50 \pm 0.58$ & $0.25 \pm 0.50$ & $2.75 \pm 0.50$ & $0.50 \pm 0.00$ & $3.00 \pm 0.81$ \\
\hline \multicolumn{7}{|l|}{ Bacteria } \\
\hline B. subtilis & $0.00 \pm 0.00$ & $0.50 \pm 0.00$ & $1.00 \pm 0.00$ & $1.00 \pm 0.00$ & $1.00 \pm 0.00$ & $1.25 \pm 0.50$ \\
\hline P. aeruginosa & $3.25 \pm 0.50$ & $4.00 \pm 0.00$ & $4.50 \pm 0.58$ & $6.75 \pm 0.96$ & $0.50 \pm 0.00$ & $2.00 \pm 0.00$ \\
\hline
\end{tabular}

For value $0.00 \pm 0.00$ no growth inhibition zone or growth underneath the sample was observed 
a
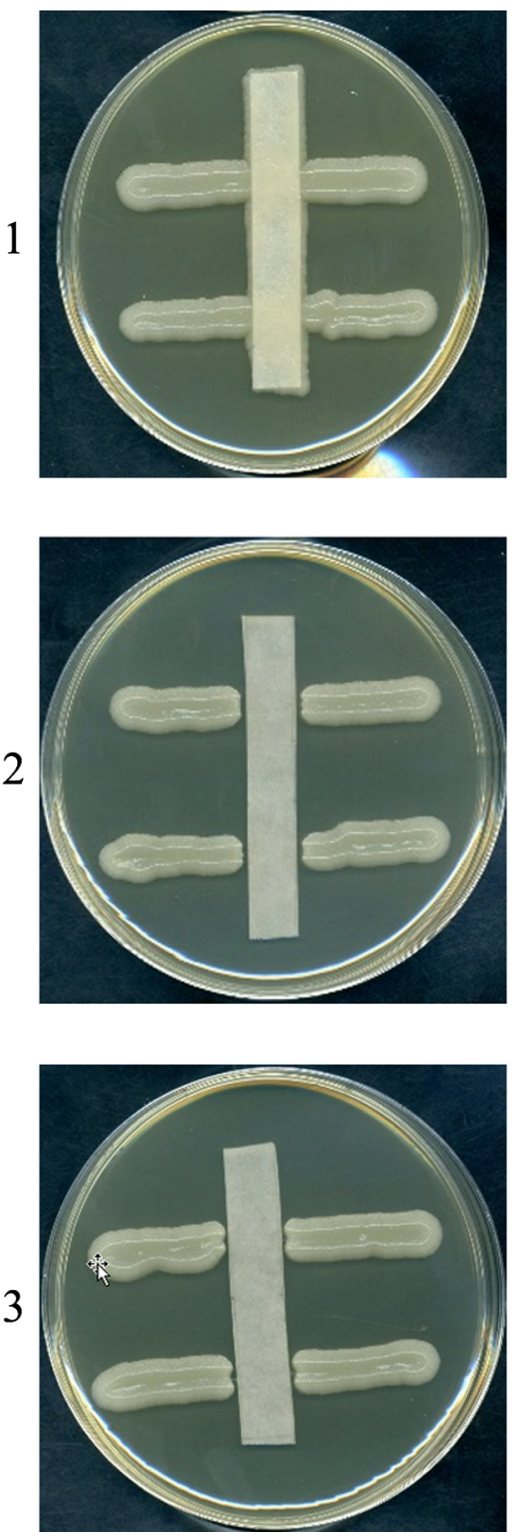

b
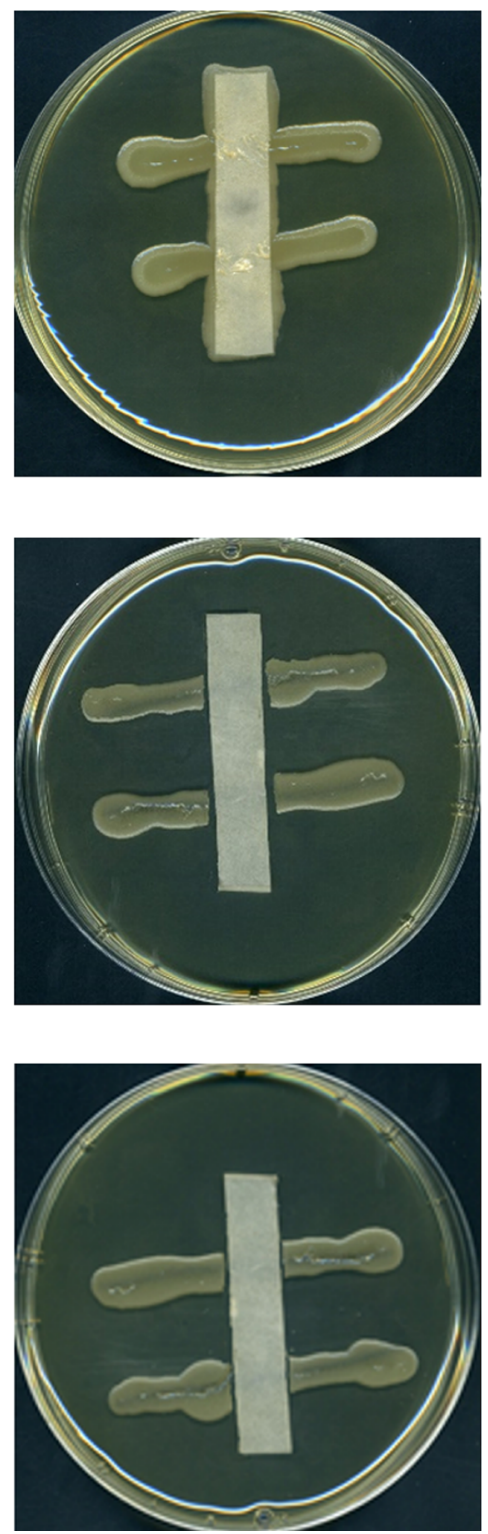

C
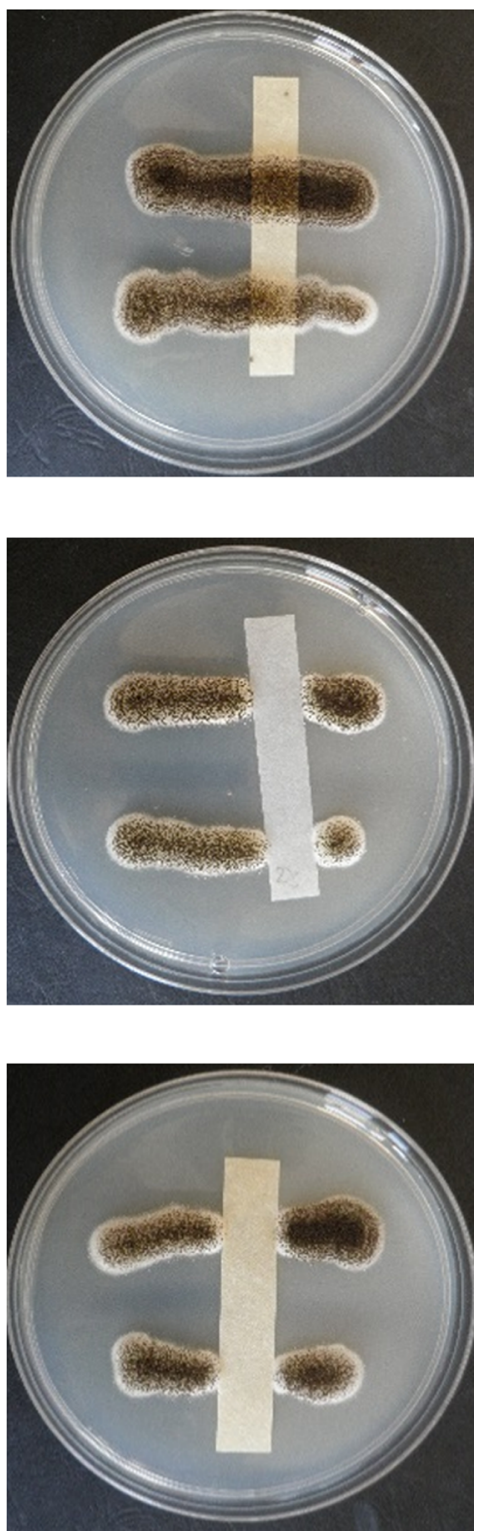

Fig. 2 Zones of inhibition against $\mathbf{a}-B$. subtilis, $\mathbf{b}-P$. aeruginosa and $\mathbf{c}-A$. brasiliensis for samples $\mathbf{1}-$ without biocides, $\mathbf{2}-$ containing monomeric surfactant DDAC and 3-gemini surfactant C6 applied using the spray method

possess significantly better activity against Gram negative bacteria. Such bacteria are characterized by an outer lipid-protein layer, which is composed of lipopolysaccharides that give the cell a negative charge. As revealed by Nechita et al. (2015), strong electrostatic interaction between a cell and biocide has an impact on antimicrobial activity.

A comparative analysis of the antimicrobial properties of paper in terms of the structure of surfactants showed that for the majority of the tested samples the zones of growth inhibition were larger in the case of the monomeric compound. Of the tested moulds $A$. versicolor and $T$. viride (spray) and $P$. aurantiogriseum (coating) were the exceptions, as the application of gemini surfactant contributed to increase the size of the inhibition zones. No significant differences were noted depending on the method of application. For DDAC applied by the coating method, better 
antimicrobial activities were obtained for the 4 strains of moulds, whereas when it was sprayed there was improved activity against 2 strains. The opposite relationship between coating and spraying was observed for the dimeric compound. There was a slight improvement with coating against 3 strains of mould, while spraying improved activity against $P$. chrysogenum, A. versicolor and $T$. viride. Turning to the impact of the application method on bacteria, larger zones of inhibition were visible for $B$. subtilis in the case of samples containing sprayed biocides (Fig. 2). A similar trend was detected for P. aeruginosa when both monomeric and dimeric compounds were applied to the paper by coating.

Antifungal properties of paper modified with surfactants-TAPPI T-487 test

The next step of the research assessed the effectiveness of the tested surfactants for the preservation of paper according to the TAPPI T-487 test employed by industry. The paper samples were placed on a mineral medium without a source of carbon and inoculated with mould spores standardized to $10^{2}$ and $10^{6}$ conidia $/ \mathrm{ml}$. The results are presented in Table 5 .

After 21 days of incubation, no mould growth was observed for any sample modified with monomeric or gemini surfactants. Based on the results of the TAPPI T-487 test and the criteria presented in Table 3, it was found that all tested paper samples were resistant to all 5 studied strains of moulds. Growth of moulds was observed only on the surface of the control samples after 7 days of incubation, while after 21 days the surface of the paper was fully covered with fungal spores (Table 5).

Ziaee et al. (2014) report that paper coated with starch modified with a type of guanidine polymer PHGH $\left(1.744 \mathrm{~g} / \mathrm{m}^{2}\right)$ also exhibited high antimicrobial activity against C. globosum. Furthermore, 4,4'bispyridinum diquaternary ammonium salt at a concentration of $0.05 \%$ immobilized on $\mathrm{ZnO}$ successfully preserved paper against Geotrichum candidum (Nechita et al. 2015). However, the composite (3-chlor-2hydroxipropyl)-trimethyl ammonium chloride (Quat188) with chitosane protected paper only against Penicillium sp., regardless of how many layers were applied (Nechita et al. 2015). Therefore, it is crucial to choose an appropriate biocide to preserve paper against microbial growth. Chemical compounds can inhibit the growth of bacteria and moulds, but functionalization with additional substances may hinder their antimicrobial effect. This was confirmed by Sequeira et al. (2017a), who used clotrimazole with calcium hydroxide as a deacidification substance, for paper conservation.

Antimicrobial properties of paper modified with surfactants-a quantitative method

The antimicrobial properties of the modified paper samples were assessed on the basis of a quantitative analysis of the number of bacteria and fungal spores that were able to survive on the surface of the paper after $24 \mathrm{~h}$. The results are presented in Table 6.

When the results obtained at $\mathrm{t}=0 \mathrm{~h}$ for the samples modified with biocides are compared with those for the control sample (paper without biocide), it will be noticed that there was a marked reduction in the number of spores and bacteria. In the case of fungal spores, this reduction was in the range of $0.42 \mathrm{log} /$ $10 \mathrm{~cm}^{2}$ for $T$. viride (1/C6 coated sample) to $1.92 \mathrm{log} /$ $10 \mathrm{~cm}^{2}$ for $P$. chrysogenum (DDAC sprayed sample). By comparison, the decrease in the number of bacteria cells at $\mathrm{t}=0 \mathrm{~h}$ ranged from $2.01 \log / 10 \mathrm{~cm}^{2}$ for $B$. subtilis (C6 sprayed sample) to $3.02 \mathrm{log} / 10 \mathrm{~cm}^{2}$ for $P$. aeruginosa (2/DDAC coated sample).

Spray application of the biocides resulted in a slightly greater difference in the number of spores (0.1-0.5 log). The coated samples provided improved inhibition against bacteria $(0.2-0.8 \mathrm{log})$. Slightly better results were obtained for the monomeric compound, although the maximum difference from the dimeric compound was only $0.5 \mathrm{log}$. After $24 \mathrm{~h}$ of treatment, the quantities of both spores and bacteria were reduced to below $1 \log / 10 \mathrm{~cm}^{2}$ in all samples containing biocides. The reduction coefficient calculated from Eq. (1) reached 99.9\%. Preliminary studies had suggested that $A$. brasiliensis would be the least sensitive of the moulds to the biocides incorporated in paper. For this reason, the changes in the total counts of the spores of this fungus were measured after $0,1,3$, 6 and $24 \mathrm{~h}$.

For all samples of paper containing biocides, the number of A. brasiliensis spores reduced by $1.10-1.88$ $\log$ at $\mathrm{t}=0 \mathrm{~h}$ (Fig. 3). Over the following hours, in almost every case, the reduction coefficient was $99.9 \%$. The samples which were coated with a thin layer of the monomeric or dimeric surfactants were the 
Table 5 Macroscopic observation of mould growth on paper samples modified with surfactants after 21 days of incubation

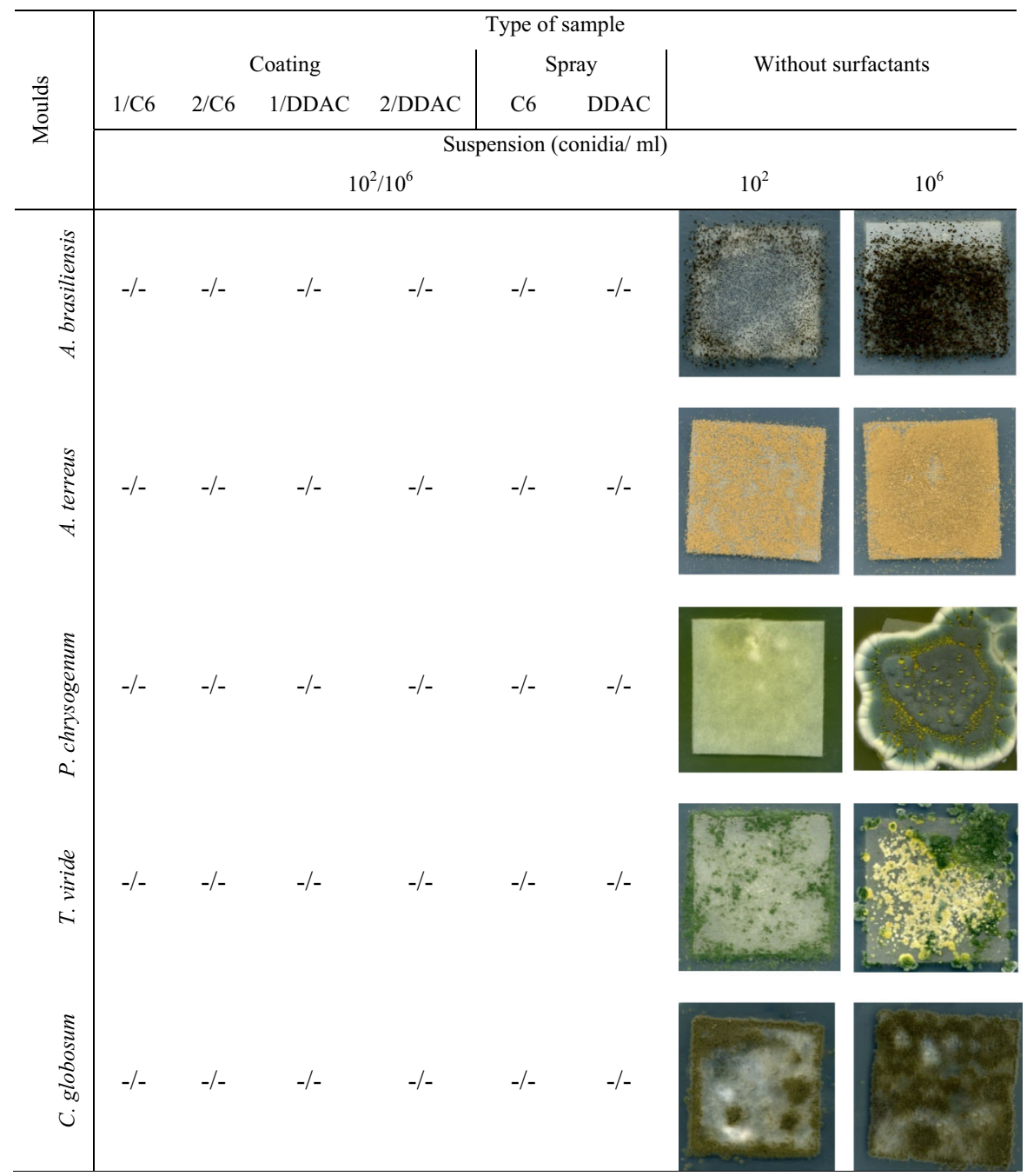

-No growth observed

exception. For the sample containing gemini surfactant 1/C6, the number of spores of A. brasiliensis was $3.64 \log$ after $1 \mathrm{~h}$, dropping to $2.02 \log$ after $3 \mathrm{~h}$, and was already below $1 \log$ after $6 \mathrm{~h}$. For the 1/DDAC sample, the number of spores recorded after $1 \mathrm{~h}$ was $1.26 \mathrm{log}$, while the number per $10 \mathrm{~cm}^{2}$ of paper was $<1 \log$.

Surfactants applied on paper by spraying or coating had not been previously studied as antimicrobial agents for the preservation of paper. However, a number of recent works have reported the modification of paper with various compounds, to obtain antimicrobial activity. Similarly good results to those obtained in our study (100\% reductions in the number of microorganisms) were obtained by Li et al. (2016) and Amini et al. (2016), both of whom used nanosilver as the antimicrobial agent. $\mathrm{Li}$ et al. applied silver nanoparticles immobilized onto chitin nanocrystals (CNC), which they coated on paper at $14 \mathrm{mg} / 100 \mathrm{~cm}^{2}$ and $20 \mathrm{mg} / 100 \mathrm{~cm}^{2}$. Amini et al. used nanofibrillated cellulose (NFC) with silver nanoparticles. The paper was coated by filtration and deposition of NFC/Ag layers on the surface. The coating weight was $5-25 \mathrm{mg} / 100 \mathrm{~cm}^{2}$. In both cases, the reduction rate of $E$. coli and $S$. aureus after $24 \mathrm{~h}$ was $100 \%$ for samples containing $14 \mathrm{mg} / 100 \mathrm{~cm}^{2}$ of CNC/Ag ( $\mathrm{Li}$ 
Table 6 Changes in the total counts of bacteria and fungal spores $\left(\log / 10 \mathrm{~cm}^{2}\right)$ on the paper samples after 0 and $24 \mathrm{~h}$ of treatment with monomeric (DDAC) and dimeric (C6) surfactant

\begin{tabular}{|c|c|c|c|c|c|c|c|c|c|}
\hline \multirow[t]{4}{*}{ Microorganisms } & \multicolumn{9}{|c|}{ Type of sample } \\
\hline & \multicolumn{4}{|c|}{ Coating } & \multicolumn{2}{|c|}{ Spray } & \multirow[t]{2}{*}{ All* } & \multicolumn{2}{|c|}{ Without surfactants } \\
\hline & \multicolumn{7}{|c|}{ Time of incubation (h) } & & \\
\hline & 0 & & & & & & 24 & 0 & 24 \\
\hline \multicolumn{10}{|l|}{ Moulds } \\
\hline A. brasiliensis & 5.59 & 5.48 & 5.61 & 5.53 & 5.52 & 5.12 & $<1.0$ & 6.45 & 6.11 \\
\hline A. terreus & 5.54 & 5.21 & 5.37 & 4.67 & 5.12 & 4.82 & $<1.0$ & 6.20 & 5.81 \\
\hline P. chrysogenum & 5.60 & 5.41 & 5.62 & 5.15 & 5.36 & 4.64 & $<1.0$ & 6.58 & 5.78 \\
\hline T. viride & 5.69 & 5.54 & 5.68 & 5.25 & 5.38 & 5.11 & $<1.0$ & 6.11 & 6.00 \\
\hline C. globosum & 5.72 & 5.56 & 5.53 & 5.30 & 5.64 & 5.23 & $<1.0$ & 6.18 & 6.05 \\
\hline \multicolumn{10}{|l|}{ Bacteria } \\
\hline Bacillus sp. & 4.57 & 4.12 & 4.4 & 4.32 & 4.94 & 4.64 & $<1.0$ & 6.95 & 8.04 \\
\hline P. aeruginosa & 4.82 & 4.55 & 4.52 & 4.32 & 4.75 & 4.66 & $<1.0$ & 7.24 & 8.31 \\
\hline
\end{tabular}

All* values for all samples from 1/C6 coating to DDAC spray were the same

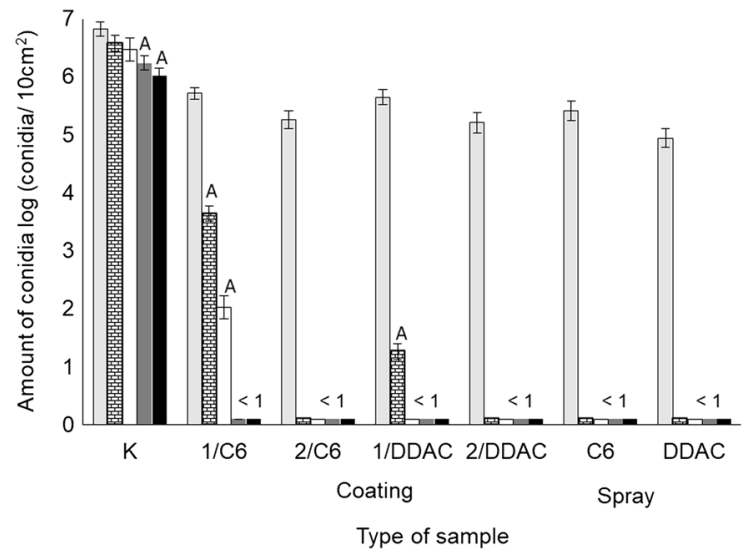

Fig. 3 Change in the total counts of A. brasiliensis ATCC 16404 ( $\log$ conidia/ $/ 10 \mathrm{~cm}^{2}$ ) on the surfaces of samples modified with surfactants after $0-24 \mathrm{~h}$ (light grey- $0 \mathrm{~h}$, brick pattern$1 \mathrm{~h}$, white $-3 \mathrm{~h}$, dark grey-6 h, black $24 \mathrm{~h}$ ). A- reduced value of $\log 10$ amount of conidia differed significantly from the sample at the time $0 \mathrm{~h}(p<0.005)$

et al. 2016) and $20 \mathrm{mg} / 100 \mathrm{~cm}^{2}$ (Amini et al. 2016) of $\mathrm{NFC} / \mathrm{Ag}$.

Significant reductions (more than $4 \log$ ) in the amount of Bacillus genus on the surface of modified paper have also been reported by Vartiainen et al. (2004) and Martins et al. (2013). Vartiainen et al. tested paper samples coated with chitosan dissolved in 1.6-6.4\% lactic acid against B. subtilis. Martins et al. tested paper modified with nanofibrillated cellulose and $\mathrm{ZnO}$ nanoparticles against $B$. cereus.

Studies on the resistance of paper modified with various biocidal compounds to moulds are usually based on colony area measurements after 4-30 days of incubation (ASTM D 2020 method) or macroscopic observation after 7-21 days of incubation (TAPPI T487), from which the percentage inhibition of fungal growth is calculated. In our work, complete inhibition of mould growth was achieved for all paper samples modified with both mono and gemini surfactants (Table 6). Several papers on the antifungal activity of paper, reporting highly effective modification with different substances, have been published by Sequeira et al. (2012, 2017a, b). Paper containing pure clotrimazole was found to have anti-fungal activity against A. niger and $P$. chrysogenum after 15 days of incubation. However, the interaction of this compound with $\mathrm{Ca}(\mathrm{OH})_{2}$ nanoparticles, which have deacidification properties in isopropanol, caused a reduction in growth inhibition to only 4 days. These compounds were found to be almost completely ineffective against C. globosum (Sequeira et al. 2017a). Much better results were achieved by the same authors (Sequeira et al. 2017b) for paper mixed with methylparaben and propylparaben, and also when these substances were combined with calcium propionate, which like 
$\mathrm{Ca}(\mathrm{OH})_{2}$ has deacidification properties. No growth of A. niger, $P$. chrysogenum or $C$. globosum, which belongs to Ascomycetes, was observed during the study after 15 or even 30 days.

\section{Conclusion}

The results presented in this paper show that introducing both monomeric DDAC (didecyldimethylammonium chloride) and dimeric hexamethylene-1,6bis-(N, N-dimethyl-N-dodecylammonium bromide) C6 surfactants onto the surface of paper provides very good protection against microorganisms. Both coating and spraying were similarly effective, allowing manufacturers to choose either method. Possible uses of paper modified with the tested surfactants include: as a packaging material for the protection of works of art, documents, or insulating material used in construction; for packaging pharmaceuticals, herbs, cut flowers and seeds; for the production of bags for the disposal of animal faeces and organic waste and in the production of toiletry materials. As part of our research, we further analysed changes in the physicochemical and technological parameters of the modified paper. The results will be published in a separate publication, but they confirm the potential of applying surfactants to paper.

\section{Compliance with ethical standards}

Conflict of interest The authors declare that they have no conflict of interest.

Open Access This article is distributed under the terms of the Creative Commons Attribution 4.0 International License (http:// creativecommons.org/licenses/by/4.0/), which permits unrestricted use, distribution, and reproduction in any medium, provided you give appropriate credit to the original author(s) and the source, provide a link to the Creative Commons license, and indicate if changes were made.

\section{References}

AATCC Test Method 147-2011. Antibac-terial activity assessment of textile ma-terials: Parallel Streak Method

AATCC Test Method 100-2012. Antibacterial finishes on textile materials

Akbari S, Michal Kozłowski R (2018) A review of application of amine-terminated dendritic materials in textile engineering. J Text Inst 110(3):460-467
Amini E, Azadfallah M, Layeghi M, Talaei-Hassanloui R (2016) Silver-nanoparticle-impregnated cellulose nanofiber coating for packaging paper. Cellulose 23:557-570. https://doi.org/10.1007/s10570-015-0846-1

Battisti R, Fronza N, Vargas Junior A, Mello da Silveira S, Damas MSP, Novy Quadri MG (2017) Gelatin- coated paper with antimicrobial and antioxidant effect for beef packaging. Food Packag Shelf Life 11:115-124. https:// doi.org/10.1016/j.fpsl.2017.01.009

Fabbri AA, Ricelli A, Brasini S, Fanelli C (1997) Effect of different antifungals on the control of paper biodeterioration caused by fungi. Int Biodeter Biodegr 39:61-65

Flemming HC, Meier M, Schild T (2013) Mini-review: microbial problems in paper production. Biofouling 29:683-696. https://doi.org/10.1080/08927014.2013.798865

Ghorbani HR (2014) Biological coating of paper using silver nanoparticles. IET Nanobiotechnol 8:263-266. https://doi. org/10.1049/iet-nbt.2013.0039

Goyer N, Lavoie J (2001) Identification of sources of chemical and bioaerosols emissions into the work environment during secondary treatment of pulp mill effluents. Tappi J 84:2-13

Huang CY, Hsieh SP, Kuo PA, Jane WN, Tu J, Wang YN, Ko $\mathrm{CH}$ (2009) Impact of disinfectant and nutrient concentration on growth and biofilm formation for Pseudomonas strain and the mixed cultures from a fine papermachine system. Int Biodeter Biodegr 63:998-1007. https://doi.org/ 10.1016/j.ibiod.2009.07.004

ISO 5269-2:2004 Pulps-Preparation of laboratory sheets for physical testing-Part 2: Rapid-Köthen method

Jaisai M, Baruah S, Dutta J (2012) Paper modified with ZnO nanorods-antimicrobial studies. Beilstein J Nanotechnol 3:684-691. https://doi.org/10.3762/bjnano.3.78

Koziróg A, Brycki B (2015) Monomeric and gemini surfactants as antimicrobial-agents influence on environmental and reference strains. Acta Biochim Pol 62:879-883. https:// doi.org/10.18388/abp.2015_1150

Koziróg A, Kręgiel D, Brycki B (2017) Action of monomeric/ gemini surfactants on free cells and biofilm of Asaia lannensis. Molecules 22:2036. https://doi.org/10.3390/ molecules22112036

Koziróg A, Otlewska A, Brycki B (2018) Viability, enzymatic and protein profiles of Pseudomonas aeruginosa biofilm and planktonic cells after monomeric/gemini surfactant treatment. Molecules 23:1294. https://doi.org/10.3390/ molecules23061294

Li Z, Zhang M, Cheng D, Yang R (2016) Preparation of silver nano-particles immobilized onto chitinnano-crystals and their application to cellulose paper for impartingantimicrobial activity. Carbohydr Polym 151:834-840. https:// doi.org/10.1016/j.carbpol.2016.06.012

Ling Y, Luo Y, Luo J, Wang X, Sun R (2013) Novel antibacterial paper based on quaternized carboxymethyl chitosan/ organic montmorillonite/Ag NP nanocomposites. Ind Crop Prod 51:470-479. https://doi.org/10.1016/j.indcrop.2013. 09.040

Manente S, Micheluz A, Ganzerla R, Ravagnan G, Gambaro A (2012) Chemical and biological characterization of paper: a case study using a proposed methodological approach. Int Biodeter Biodegr 74:99-108. https://doi.org/10.1016/j. ibiod.2012.03.008 
Martins NCT, Freire CSR, Neto CP, Silvestre AJD, Causio J, Baldi G, Sadocco P, Trindade T (2013) Antibacterial paper based on composite coatings of nanofibrillated cellulose and $\mathrm{ZnO}$. Colloid Surf A 417:111-119. https://doi.org/10. 1016/j.colsurfa.2012.10.042

Nechita P, Bobu E, Parfene G, Dinica RM, Balan T (2015) Antimicrobial coatings based on chitosan derivatives and quaternary ammonium salts for packaging paper applications. Cellul Chem Technol 49:625-632

Pang B, Yan J, Yao L, Liu H, Guan J, Wang H, Liu H (2016) Preparation and characterization of antibacterial paper coated with sodium lignosulfonate stabilized $\mathrm{ZnO}$ nanoparticles. RSC Adv 6:9753-9759. https://doi.org/10. 1039/c5ra21434c

Pinzari F, Pasquariello G, De Mico A (2006) Biodeterioration of paper: a SEM study of fungal spoilage reproduced under controlled conditions. Macromol Symp 238:57-66. https:// doi.org/10.1002/masy.200650609

Rodríguez A, Batlle R, Nerín C (2007) The use of natural essential oils as antimicrobial solutions in paper packaging, part II. Prog Org Coat 60:33-38. https://doi.org/10.1016/j. porgcoat.2007.06.006

Sequeira SO, Cabrita EJ, Macedo MF (2012) Antifungals on paper conservation: an overview. Int Biodeter Biodegr 74:67-86. https://doi.org/10.1016/j.ibiod.2012.07.011

Sequeira SO, Laia CAT, Philips AJL, Cabrita EJ, Macedo MF (2017a) a) Clotrimazole and calcium hydroxide nanoparticles: a low toxicity antifungal alternative for paper conservation. J Cult Herit 24:45-52. https://doi.org/10.1016/j. culher.2016.12.004

Sequeira SO, Phillips AJL, Cabrita EJ, MAcedo MF (2017b) Antifungal treatment of paper with calcium propionate and parabens: short- term and long- term effects. Int Biodeter Biodegr 120:203-215. https://doi.org/10.1016/j.ibiod. 2017.03.005
Shogren RL, Doane WM, Garlotta D, Lawton JW, Willett JL (2003) Biodegradation of starch/polylactic acid/poly(hydroxyester-ether) composite bars in soil. Polym Degrad Stabil 79:405-411

Stobińska H, Zyska B (2005) Paper-manu-facturing, paper products, materials in li-brary collections. In: Zyska B, Żakowska Z (eds) Microbiology of materials, (in Polish). Publisher Lodz University of Technology, Lodz, pp 137-180

TAPPI T-487 Fungus resistance of paper and paperboard

TAPPI T-248 sp-15 Laboratory beating of pulp (PFI mill method)

Tudorachi N, Cascaval CN, Rusu M, Pruteanu M (2000) Testing of polyvinyl alcohol and starch mixtures as biodegradable polymeric materials. Polym Test 19:785-799. https://doi. org/10.1016/S0142-9418(99)00049-5

Vartiainen J, Motion R, Kulonen H, Rättö M, Skyttä E, Ahvenainen $R$ (2004) Chitosan-coated paper: effects of nisin and different acids on the antimicrobial activity. J Appl Polym Sci 94:986-993. https://doi.org/10.1002/app.20701

Wang J, Liu W, Li H, Wang H, Wang Z, Zhou W, Liu H (2013) Preparation of cellulose fiber- $-\mathrm{TiO}_{2}$ nanobelt-silver nanoparticle hierarchically structured hybrid paper and its photocatalytic and antibacterial properties. Chem Eng J 228:272-280. https://doi.org/10.1016/j.cej.2013.04.098

Ziaee Z, Xiao H, Guan Y, Fatehi P (2014) Coating PHGHmodified starch on papers to induce antimicrobial properties. BioResources 9:3632-3641

Publisher's Note Springer Nature remains neutral with regard to jurisdictional claims in published maps and institutional affiliations. 